VASCO Gil Mantas

Professor Auxiliar da Universidade de Coimbra

A LUSITÂNIA E O MEDITERRÂNEO: IDENTIDADE E DIVERSIDADE NUMA PROVÍNCIA ROMANA

"Conimbriga" XLIII (2004) p. 63-83

ABSTRACT: The geographic situation of Lusitania, due both to its proximity to the Mediterranean and Atlantic condition, allowed a very interesting cultural symbiosis in Roman times, exemplar of the way how a province close to two, so distinct realities was integrated in such a perfect manner in the Roman Empire, on which centre and outskirts knew forms of relationship far more complex than what an obsolete concept of romanization considered. Although prior to the Roman rule and continued after its disappearance, the relations between the peninsular west and the mediterranean world had in the centuries of roman presence its higher moment determining what we are today.

RESUMO: A situação geográfica da Lusitânia, pela sua proximidade ao Mediterrâneo e condição atlântica, permitiu uma interessante simbiose cultural na época romana, exemplar da forma como uma província intermediária entre duas realidades tão distintas se integrou plenamente no Império Romano, no qual centro e periferia conheceram um relacionamento bastante mais complexo do que um obsoleto conceito de romanização tem considerado.

Embora anteriores ao domínio romano, bem adaptado às condições regionais, e continuadas depois de este terminar, as relações do Ocidente peninsular com o mundo mediterrânico tiveram, nos séculos da presença romana, o seu grande momento, determinando o que hoje somos. 



\section{A LUSITÂNIA E O MEDITERRÂNEO: IDENTIDADE E DIVERSIDADE NUMA PROVÍNCIA ROMANA}

Um eminente especialista italiano, recentemente desaparecido ${ }^{1}$, Giancarlo Susini, reflectiu sobre a riqueza do espólio epigráfico do Museu de S. Miguel de Odrinhas como testemunho exemplar da presença dos modelos culturais romanos no extremo ocidental do Império, proprio verso l'Atlantico dal quale tra le pietre soffiano gli zefiri più fragranti e impetuosi ${ }^{2}$. Com esta referência, que é uma homenagem despretensiosa a um colega distinto, mergulhamos directamente no assunto da nossa comunicação, o da recepção dos padrões mediterrânicos numa das províncias da fachada atlântica do império, a Lusitânia.

O tema parece-nos suficientemente interessante para ser aqui tratado, tanto mais que o final do século encontra uma situação em que a velha problemática das fronteiras culturais ganhou de novo pertinente actualidade e, não poucas vezes, dramática expressão. A área mediterrânica continua a ser um cenário privilegiado de intercâmbios e de conflitos, ao longo do qual duas visões do mundo se defrontam, ilustrando a conhecida tese da ruptura entre as duas margens proposta há décadas por Henri Pirenne ${ }^{3}$. A situação geográfica da Lusitânia permitiu, pela sua proximidade ao Mediterrâneo e pelos factores atlânticos que condicionam o território, uma interessante simbiose cultural, exemplar da forma como uma província charneira entre duas realidades distintas se

1 Este artigo foi redigido como comunicação às III Jornadas/Congresso do Arquivo de Beja, em 1999. Como as Actas não foram editadas até à data, resolvemos publicá-lo na revista Conimbriga, sem alterações significativas. Agradecemos cordialmente a preparação das figuras ao Dr. José Luís Madeira.

2 Giancarlo Susini, A Sintra tra i "libri" scolpiti dai nostri avi, "Il Resto del Carlino”, (Bolonha), edição de 24.10.2000.

3 H. Pirenne, As cidades da Idade Média, Lisboa, 1973³, p. 9-48. 
integrou no mundo romano, um autêntico império universal onde centro e periferia conheceram formas de relacionamento mais complexas do que um obsoleto conceito de romanização permite considerar ${ }^{4}$.

As fontes literárias contemporâneas reflectem com alguma clareza a dicotomia reconhecida entre a fachada atlântica do Império, onde é possível situar mirabilia como éguas que fecundam do vento ou tritões e sereias povoando a costa 5 , e o Mare Nostrum, centro incontestado do Império e, por extensão, da própria civilização. É esta concepção de centralidade que prevalece na retórica de Élio Aristides e que se representa, através de uma iconografia exuberante, no mosaico cósmico de Mérida $^{6}$, enquanto as obras de Tácito, embora respeitando a mesma ideia, não iludem a questão da difícil recepção dos modelos romanos nas províncias atlânticas setentrionais ${ }^{7}$, profundamente diferentes dos territórios mediterrânicos. A Lusitânia e a Tingitânia, unidas pela Bética, constituíram um bloco que funcionou como um autêntico portal do Atlântico, com particular destaque para a Lusitânia, cuja evolução não pode compreender-se isolada deste contexto ${ }^{8}$.

O domínio romano na região reforçou contactos com o Mediterrâneo muito anteriores e cujo impacte na fachada atlântica da Península Ibérica começa finalmente a ser conhecido, contando com testemunhos arqueológicos incontestáveis ilustrando a presença fenícia e púnica e os horizontes orientalizantes que resultaram de processos de aculturação iniciados pelo menos a partir do século IX a. C. ${ }^{9}$. Não foram, pois, os

4 J. C. Barret, Romanization: a critical comment, "Dialogues in Roman Imperialism", Portsmouth (RI), 1997, p. 51-64. Sobre a mobilidade no Império, elemento fundamental da aculturação: R. Chevallier, Voyages et déplacements dans l'Empire romain, Paris, 1988.

5 Plínio, N. H., VIII, 166; IX, 9.

6 Élio Aristides, Oratio Romae, (Ed. e trad. de J. H. Oliver, The ruling power), Filadélfia, 1953; M. H. Quet, La mosaique cosmologique de Mérida. Propositions de lecture, "Conimbriga”, XVIII, 1979, p. 45-56; J. M. Alvarez Martínez (Ed.), El mosaico cosmológico de Mérida, "Cuadernos Emeritenses”, 12, Mérida, 1996.

7 Tácito, Agr., 30-34.

8 Vasco Mantas, Navegação, economia e relações interprovinciais. Lusitânia e Bética, "Humanitas", 50, 1998, p. 199-239 (=Mantas, Navegação).

9 Ana Arruda, “Orientalismo” e "orientalizante”. Génese e aplicação dos conceitos na Idade do Ferro do Centro/Sul de Portugal, "Homenagem a Jorge Borges de Macedo", Lisboa, 1992, p. 34-48; O comércio fenício, "História de Portugal”, (Dir. João Medina), II, Amadora, 1993, p. 17-34. 
Romanos a estabelecer o contacto entre a Lusitânia, ou o que viria a ser a Lusitânia, e o Mediterrâneo. O contributo romano foi outro, consistindo na integração de um território onde se reconheciam diferenças culturais acentuadas, como Estrabão as referiu ${ }^{10}$, num enorme espaço organizado em torno da Itália, no qual as diversidades regionais perdiam valor face aos fenómenos reprodutores dos padrões do centro do poder político.

A influência mediterrânica fez-se sentir de forma dominante, a partir de várias regiões, durante todo o período imperial, mas a província não estava isolada dos restantes territórios da fachada atlântica, mantendo contactos com a Gália, a Bretanha, a Germânia e, muito naturalmente, com a Mauritânia Tingitana ${ }^{11}$. Tal facto correspondia a uma realidade característica da Pax Romana, garante da mobilidade de pessoas e bens numa escala até então desconhecida, e à continuidade de relações marítimas anteriores, justificada pela localização do território lusitano e importância de alguns dos seus portos, com particular relevo para Olisipo (Lisboa), servindo numerosos tráficos e um rico hinterland $^{12}$. Para além dos testemunhos arqueológicos não faltam referências literárias ilustrativas da intensidade das relações marítimas entre o Mediterrâneo e o Atlântico, com escalas obrigatórias na costa lusitana, nomeadamente em autores como Plínio-o-Antigo e Élio Aristides ${ }^{13}$.

Não podemos, portanto, considerar a Lusitânia como um território isolado, sem contactos, dificilmente inserido no mundo mediterrânico gerido por Roma. É certo que estamos longe do esplendor das cidades italianas ou orientais, na maioria dos casos herdeiras de uma história civilizacional na qual Roma representa uma recém-chegada, mas bastaria invocar a importância económica e estratégica das produções provinciais para atribuir à Lusitânia uma situação menos medíocre no conjunto dos territórios romanos. Não fosse assim não teria o Édito do Má-

10 Estrabão, III, 1, 1-3. Sobre esta questão: G. C. Andreotti (Coord.), Estrabón e Ibéria: nuevas perspectivas de estudio, Málaga, 1999.

11 G. Chic García, Roma y el mar: del Mediterráneo al atlántico, "Guerra, Exploraciones y Navegación del Mundo Antiguo a la Edad Moderna”, Corunha, 1995, p. 55-89; E. Gozálbes Cravioto, Observaciones acerca del comercio de época romana entre Hispania y el Norte de Africa, “Antiquités Africaines", 29, 1993, p. 163-176.

12 Vasco Mantas, Olisipo e o Tejo, "Colóquio Temático. Lisboa Ribeirinha”, Lisboa, 1999, p. 15-41; M. Cary, The geographical background of greek and roman history, Oxford, $1950^{2}$, p. 237-238.

13 Plínio, N. H., II, 167-168; Élio Aristides, Or. Rom., XXXVI, 91. 
ximo de Diocleciano indicado a tarifa do transporte marítimo entre o Oriente e a Lusitânia ${ }^{14}$.

As relações com o espaço mediterrânico não se limitaram ao simples intercâmbio de produtos ou de artigos manufacturados, de que as estelas da Quinta de Marim, perto de Olhão (IRCP 45, 49), seguramente provenientes da actual Tunísia e trazidas para a Lusitânia através de um frete de retorno, são um bom exemplo na sua vulgaridade ${ }^{15}$. A circulação das ideias foi, talvez, mais importante, ainda que, na maioria das vezes, tenhamos que a reconstituir a partir de testemunhos materiais. A menorah figurada no disco de uma lucerna de Tróia ilustra perfeitamente o que pretendemos dizer ${ }^{16}$. A variedade de correntes culturais que o domínio romano trouxe até à Lusitânia integra valores propriamente romanos, oficiais e outros, tanto como elementos mais genericamente mediterrânicos. Uns e outros influenciaram de forma vigorosa a sociedade luso-romana.

Antes de passarmos à análise da recepção dos modelos sociais e culturais romanos na Lusitânia e da forma como foi concebida a estrutura administrativa da província não podemos deixar de aludir à natureza do território e à sua paisagem, elementos condicionadores da romanização e da imagem que hoje dela podemos recuperar (Fig. 1). As diferenças existentes entre as regiões meridionais e setentrionais da Hispânia foram postas em relevo, nos primeiros tempos do Império, por Estrabão, autor que relacionou com a situação geográfica o maior ou menor grau de desenvolvimento dos povos ibéricos, de acordo, como é natural, com os padrões mediterrânicos greco-latinos ${ }^{17}$. Esta visão determinista da cultura e da história, que tão grande êxito conheceu nos séculos XIX e XX, reflecte factores naturais que podemos considerar de

14 Jorge de Alarcão, A produção e a circulação dos produtos, "Nova História de Portugal", I, Lisboa, 1990, p. 409-411; M. Giachero, Edictum Diocletiani et collegarum de pretis rerum venalium in integrum restitutum e latinis graecisque fragmentis, I-II, Génova, 1974, p. 220, 224.

15 Vasco Mantas, A cidade luso-romana de Ossonoba, “Actas del I Colóquio de História Antigua de Andalucia”, Córdova, 1993, p. 535. Para uma interpretação valorizando a diferença entre o suporte e a escrita em termos sociais, sem relação com a origem das peças: José d'Encarnação, A necrópole romana da Quinta de Marim (Olhão), “Anais do Município de Faro", XXI, 1991, p. 231-241.

16 Vasco Mantas, Navegação, p. 235.

17 Estrabão, III, 1, 2; 1, 6. Sobre esta questão: P. Thollard, Barbarie et civilisation chez Strabon. Étude critique des livres III et IV de la Géographie, Paris, 1987. 
ordem essencial, uma vez que sugerem uma divisão Norte-Sul da Península, ou, se quisermos simplificar, a existência de uma Hispânia atlântica e de outra mediterrânica.

Esta divisão pode pressentir-se logo no início da presença romana com a definição de duas grandes províncias, a Hispania Citerior e a Hispania Ulterior, a última das quais se vai tornando progressivamente atlântica. Ao longo da história estas duas componentes da mesma entidade geográfica nunca deixaram de estar presentes, de uma ou de outra forma, originando marcas culturais indeléveis. A leitura de autores tão distintos como al-Rasis, que fala em duas áreas peninsulares individualizadas, uma a nascente e outra a poente, ou Miguel Torga, interpretando as razões do que existe de conflituoso na alma portuguesa ${ }^{18}$, é muito explícita quanto a esta dualidade.

O território da província lusitana corresponde nitidamente a duas zonas que os geógrafos identificam, com uma ou outra divergência de pormenor, a partir das características climáticas e paisagísticas, uma de influência atlântica e outra de influência mediterrânica ${ }^{19}$. Onde situar o limite entre as duas referidas zonas não é difícil, em termos naturais, mas a determinação da fronteira entre o Norte atlântico e o Sul mediterrânico no tocante a aspectos culturais já não se revela tão simples. Lisboa tem sido considerada, com alguma razão, o último porto mediterrânico, não se afastando muito esta classificação do conceito geográfico romano de autores como Plínio-o-Antigo e Solino, que situavam no Promontorium Magnum (Cabo da Roca) o ponto de transição entre o Oceano Atlântico, a sul, e o Oceano Gálico, para norte ${ }^{20}$.

Orlando Ribeiro considerava a paisagem perto de Conimbriga como a primeira com afinidades mediterrânicas a norte do Tejo, situando imediatamente ao Mondego o limite entre o Norte e o Sul ${ }^{21}$. Esta proposta, embora afastando do vale do Tejo, fronteira tradicional da Lu-

18 E. Lévi-Provençal, La description de l'Espagne d'Ahmad al-Râzi, 'Al-Andalus', 18, 1953, p. 89-91; Miguel Torga, Diário, II, Coimbra, 1977 4, p. 27.

19 Orlando Ribeiro, Portugal, o Mediterrâneo e o Atlântico, Lisboa, 1963, p. 178-179, 187-188 (=Orlando Ribeiro, Portugal); Barry Cunllife, Diversity in landscape: the geographical background to urbanism in Iberia, "Social Complexity and the Development of Towns in Iberia", Oxford, 1995, p. 14.

20 A. Siegfried, Suez, Panama et les routes maritimes mondiales, Paris, 1940, p. 31; Plínio. N.H., IV, 114; Solino, Memor., XXIII, 5.

21 Orlando Ribeiro, Portugal, p. 166-167; Orlando Ribeiro et alii, Geografia de Portugal, II, Lisboa, 1988, p. 457. 
sitânia, a referida linha divisória, acaba por incluir na área assim definida os Turdulorum oppida da fachada ocidental da província, aproximando-se significativamente da fronteira sul da área principal da chamada Cultura Castreja, onde Plínio fazia a separação entre populi e oppida $^{22}$. A quase coincidência da fronteira entre as áreas mais abertas aos modelos mediterrânicos, na época romana, com as duas grandes regiões naturais que aqui consideramos mostra que estas correspondem a dois ambientes culturais diferenciados, condicionados por factores geográficos. A simples comparação das cidades privilegiadas situadas a sul do Tejo com as civitates a norte deste rio facilmente demonstra a coexistência de duas realidades significativamente distintas.

Seja como for, a diversidade geográfica do território lusitano determinou a presença de estruturas sociais e económicas distintas, consoante as regiões, do que resultou a adequação dos padrões romanos a esta ou aquela realidade indígena. $\mathrm{Na}$ verdade, não existe um procedimento uniforme por parte da administração romana para a totalidade do território, nem assim poderia ter acontecido. As situações proto-urbanas que encontraram no Sul eram desconhecidas no interior e na região setentrional, pelo que foi naquela região, de há muito influenciada pelo Mediterrâneo, que os modelos romanos se estabeleceram mais rapidamente e de forma sistemática. Tal facto resultou de uma opção estratégica e não de uma pretendida incapacidade de romanizar as referidas regiões, excluídas dos grandes planos de colonização conhecidos no Sul e onde a urbanização serviu, fundamentalmente, finalidades administrativas $^{23}$.

Quando referimos a Lusitânia em termos territoriais recorremos aos limites da província romana tal como ela foi definida pela derradeira reforma levada a cabo por Augusto. Trata-se de uma solução de facilidade que não corresponde aos limites da Lusitânia no período republicano nem aos que teve nos primeiros anos do Império. Verifica-se, portanto, que o conceito evoluiu ao longo do tempo, variando a área abrangida pelo que era inicialmente uma parte da Hispania Ulterior. A evolução territorial e as hesitações que as várias mudanças dos limi-

22 Plínio, N.H., IV, 112.

23 Vasco Mantas, O espaço urbano nas cidades do Norte da Lusitânia, "Los Orígenes de la Ciudad en el Noroeste Hispánico", I, Lugo, 1998, p. 355-391; W. S. Hanson, Administration, urbanisation and acculturation in the roman west, "The Administration of the Roman Empire. 241 BC-AD 193”, Exeter, 1988, p. 53-68. 
tes lusitanos demonstram são, em parte, consequência da incorporação de regiões diferenciadas e da concepção romana da geografia da Península Ibérica, situando a Lusitânia a norte e limitada pelo Oceano Gálico.

Como se verificou noutras situações relacionadas com a expansão romana, a Lusitânia não correspondia a um território homogéneo à data da chegada dos Romanos, ao contrário de territórios como o do Egipto, por exemplo, de fronteiras perfeitamente definidas. No início do século II a. C., o termo Lusitânia, mais que referir uma área geográfica bem definida e ocupada por um único povo, correspondia a um conceito geoestratégico, em grande parte determinado pela importância da resistência lusitana à conquista romana, como Estrabão claramente referiu ${ }^{24}$. Os Lusitanos constituíram um grupo de populi, sendo o nome utilizado como um colectivo pelos Romanos, como sucedeu noutras regiões, circunstância muito vulgar em situações coloniais de todas as épocas ${ }^{25}$. Assim, a Turdetânia, a Céltica e a Lusitânia representam sectores operacionais da Hispania, circunstância que explicará a ambiguidade das fontes literárias romanas do período republicano quanto à geografia dos territórios.

O primeiro recontro entre Lusitanos e Romanos verificou-se, segundo parece, em 194 a. C., muito longe do território lusitano, perto de Hispalis (Sevilha). O primeiro exército romano a operar na Lusitânia, se não houve tropas no estuário do Tejo em data anterior, foi o de L. Postúmio Albino, que atravessou território lusitano da actual Beira Baixa para atacar os Vaceus ${ }^{26}$. Como já referimos, Estrabão situava os Lusitanos a norte do Tejo, mas esta indicação não esclarece satisfatoriamente o problema da sua localização, pois sabemos da existência a norte do mesmo rio de Túrdulos e de Vetões. Em linhas muito gerais podemos admitir que a região lusitana ficava compreendida entre estes dois povos e os rios Douro e Tejo, o que não representa uma solução satisfatória.

O nosso problema consiste em tentar precisar onde estão os Lusitanos nos finais da II Idade do Ferro ou, pelo menos, determinar qual a sua área de implantação principal. Esta questão é de primordial importância para a definição da identidade lusitana na época imperial, uma

24 Estrabão, III, 3, 3.

25 Jorge de Alarcão, O domínio romano em Portugal, Mem Martins, 1989, p. 15-16 (=Alarcão, Domínio).

26 Tito Lívio, H.R., XXXVI, 1; XL, 47. 
vez que é evidente a não concordância entre o território e o povo. Tradicionalmente situam-se os Lusitanos na zona da Serra da Estrela, identificada com o Mons Herminius. Todavia, a quase falta de vestígios arqueológicos na área restrita da referida serra levou Jorge de Alarcão a propor que se considere a localização dos Lusitanos na Cova da Beira e no Alto Alentejo, mais de acordo com a situação existente nos inícios do século II a. C. e com os testemunhos da antroponímia indígena nas inscrições luso-romanas do nordeste alentejano ${ }^{27}$. Ainda que Estrabão tenha referido a transferência de lusitanos para sul do Tejo, a verdade é que a importância das cidades lusitanas indicadas por Ptolomeu a sul deste rio sugere um povoamento que dificilmente resultará de tais transferências, mas sim de uma presença anterior, da qual temos um indício significativo na atribuição de Nertobriga (Frejenal de la Sierra) aos Lusitanos, por Políbio ${ }^{28}$.

De tudo o que dissemos conclui-se que a definição das fronteiras da Lusitânia no século II a. C. é muito difícil. Não obstante se fazer recuar a 197 a. C. a criação de duas províncias hispânicas, de acordo com Tito Lívio, a verdade é que se trata de simples ratificação de uma situação de facto, nomeando o Senado dois magistrados dotados de imperium cuja missão era a de actuar em zonas de guerra ${ }^{29}$. É possível que a organização das duas províncias, no sentido territorial do termo, se tenha verificado apenas depois de alcançada alguma estabilidade com as vitórias sobre os Lusitanos e Celtiberos na segunda metade do século II a. C. A comissão de senadores enviada à Península Ibérica para reorganizar os territórios, que é dada a conhecer por Apiano, parece confirmar tal hipótese ${ }^{30}$. De qualquer forma, o limite setentrional da Citerior e da Ulterior corresponde a uma fronteira em movimento, dependente da evolução da conquista.

Um dos primeiros indícios da futura cisão em duas províncias da Ulterior ocorre quando César alude ao dispositivo militar pompeiano na Península, informando que Petreio dispunha de duas legiões para o sec-

27 Jorge de Alarcão, Etnografia da fachada atlântico ocidental da Península Ibérica, "Complutum", 2-3, 1992, p. 344-345: José d'Encarnação, Inscrições romanas do conventus Pacensis, Coimbra, 1984, p. 843, 777 (=IRCP).

28 Políbio, XXXV, 2.

29 Tito Lívio, H.R., II, 40, 14; XXXII, 27, 6.

30 Apiano, Iber., 99; E. Albertini, Les divisions administratives de l'Espagne romaine, Paris, 1923, p. 20-21. 
tor a norte do Guadiana e Varrão de duas outras, para a região entre aquele rio e Castulo $^{31}$.

A inevitável reorganização desta grande província coube a Augusto, na sequência da conquista das terras nortenhas que concluiu a ocupação da Hispânia, um dos primeiros objectivos do imperador. A discussão sobre a data e os motivos que levaram à divisão da Ulterior em duas províncias, Bética e Lusitânia, continua aberta, apesar de algum consenso em torno do carismático ano 27 a. C., indicado por Dião Cássio, e de motivações de ordem político-estratégica ${ }^{32}$, resultantes da nova ordem institucional romana ${ }^{33}$. Porém, uma tal iniciativa antes do fim das campanhas no Norte não tem sentido, tanto mais que o problema da autoridade de Augusto, baseada num imperium de tipo proconsular, válido para as províncias fronteiriças, como eram então a $C i$ terior e a Ulterior, não pode ser invocado como causa. A divisão não deve ter-se verificado antes de 25 a. C., ano da fundação da colónia de Augusta Emerita que se relaciona com o estabelecimento de numerosos soldados licenciados ${ }^{34}$, ou mesmo mais tarde, talvez em 22 a. C., quando encontramos L. Séstio Quirinal Albiniano exercendo funções de categoria consular na Península. Nesse ano, a Narbonense foi transferida para a administração senatorial e no ano anterior Augusto recebera a tribunitia potestas plena e foi investido de um imperium maius que lhe atribuiu poderes sobre todas as províncias ${ }^{35}$. A criação da província não correspondeu a uma definição territorial imutável, facto que se deve atribuir às dúvidas quanto ao melhor modelo administrativo adaptado às realidades do que podemos designar como Grande Lusitânia.

31 César, Bell. Civ., I, 38, 1-2.

32 J. Francisco Martín, Conquista y romanizacion de Lusitania, Salamanca, 1989, p. 92-94.

33 Dião Casio, LIII, 12, 4; P. Le Roux, L'armée romaine et l'organisation des provinces ibériques d'Auguste à l'invasion de 409, Paris, 1982, p. $54-57$ (=Le Roux, Armée).

34 Le Roux, Armée, p. 69-72; G. Fabri, La tribu Papiria di Augusta Emerita, "Emerita Augusta", Madrid, 1976, p. 33-42. Sobre o povoamento pré-romano da zona onde foi estabelecida a colónia: J. J. Enríquez Navascués, La Mérida prerromana y el poblamiento pre y protohistorico de su comarca, "Mérida. Ciudad y Patrimonio", 1, 1996, p. 30-43.

35 F. De Martino, Storia della costituzione romana, IV, 1-2, Nápoles, 1962, p.168-170; P. Petit, La paix romaine, Paris, 1967, p. 125-127, 213-220. 
Vejamos então como evoluíram os limites provinciais. Parte dos territórios conquistados no Noroeste foram incorporados na nova província, como testemunham Estrabão e Plínio-o-Antigo. O primeiro indica que a Lusitânia se estende entre o Guadiana e o Douro, mas que anteriormente ultrapassava este rio, uma vez que os Galaicos eram antes denominados Lusitanos ${ }^{36}$; Plínio, baseando-se em obras de Agripa, refere a inclusão na Lusitânia da Calécia e das Astúrias ${ }^{37}$. Esta primeira organização durou pouco. Razões militares, económicas e culturais levaram ao recuo e à fixação definitiva da fronteira setentrional no Douro. Ainda que a existência de uma Provincia Transduriana em 15 a. C. deva ser considerada cautelosamente ${ }^{38}$, a data proposta por Dião Cássio para a reorganização da Hispânia, 14 a. C., parece próxima da realidade. Não faltam, para este reduzido período entre 16 e 14 a. C. testemunhos de alterações significativas de tipo político e administrativo associadas a uma actividade colonizadora bem documentada. A este horizonte cronológico corresponderá a reorganização territorial da província, a situar provavelmente em 16 a. C. 39 .

O quadro territorial então estabelecido não sofreu posteriormente alterações significativas, centrando-se a atenção dos especialistas na questão da fronteira sul, que Plínio e Pompónio Mela situam no Guadiana ${ }^{40}$. O rio Ana servia realmente de limite entre a Lusitânia e a Bética no seu curso inferior, mas a partir do ponto de confluência do Chança e até à zona de Lacinimurga a fronteira corria sempre a sul do Guadiana. A vasta área assim demarcada apenas em parte correspondia à Lusitânia tradicional e os Lusitanos serviram de epónimo a um território onde habitavam povos distintos, administrativamente englobados na denominação genérica de Lusitanos (Fig. 2). Que assim eram provam-no amplamente as fontes escritas, especialmente quando reflectem

36 Estrabão, III, 3, 2-3; 4, 20.

37 Plínio, N.H., IV, 118; Amílcar Guerra, Plínio-o-Velho e a Lusitânia, Lisboa. 1995 , p. 114.

38 P. Le Roux, L'Edictum de Paemeiobrigensibus. Un document fabriqué?, "Minima Epigraphica et Papyrologia", IV, 6, 2001, p. 331-336 ; F.Costabile/O.Licandro, Tessera Paemeiobrigensis. Un nuovo editto di Augusto dalla Transduriana provincia e l'imperium proconsulare del princeps, "Minima Epigraphica et Papyrologica", Separata, I, Roma, 2001.

39 Dião Cássio, LIV, 25; R. Syme, A governor of Tarraconensis, "Epigraphische Studien", 8, 1969, p. 126; Le Roux, Armée, p. 69-72.

40 Plínio, N.H., III, 6; IV, 115; Mela, II, 87. 
limites internos e alterações dos mesmos. A própria capital lusitana, Emerita Augusta, é situada no território da Turdetânia por Estrabão, enquanto Plínio e Higino a situam na Vetúria e Ptolomeu entre os Lusita$\operatorname{nos}^{41}$.

Particularismos e afirmações de identidade deixaram traços que nos permitem apreender a diversidade de situações existentes na Lusitânia imperial. Tais diferenças justificarão, pelo menos parcialmente, a desigual evolução das civitates e, em certos casos, o falhanço do processo, como pode ter acontecido com Talabriga e Arandis ${ }^{42}$. A repartição geográfica dos termini augustales sugere que eles tenham sido levantados prioritariamente em áreas de maior instabilidade e em relação com rectificações de fronteiras entre populi, como no caso do marco de Guardão (Fig. 3), na Serra do Caramulo, onde se refere uma causa conhecida como motivo para esta demarcação do ano 4/5, de iniciativa do governador Q. Articuleio Régulo43.

Uma série de epígrafes do século II refere a província oficialmente como Provincia Lusitaniae et Vettoniae (CIL II 484, 485, 1178; CIL VI 31856). Esta circunstância, além de reflectir, eventualmente, a existência de duas procuradorias financeiras, uma em Mérida e outra em Lisboa, atribui um relevo especial aos Vetões, povo que Ptolomeu situava no oriente da Lusitânia ${ }^{44}$, demonstrando, mais uma vez, a diversidade populacional da província e as características artificiais da Lusitânia como território administrativo. Esta mesma artificialidade é patente no facto de terem persistido laços institucionais entre as duas províncias outrora reunidas na Hispania Ulterior, sobretudo no campo financeiro e económico, caso da procuradoria comum para a vicesima hereditatium, com sede na Bética (CIL II 2029). As relações económicas lusitanas foram marcadas durante o Alto Império pelo predomínio bético, sobretudo visível no comércio marítimo orientado para o Mediterrâneo, predomínio de que a inscrição olisiponense em honra de L. Caecilius

41 Estrabão, III, 2, 15; Plínio, N.H., III, 13; Higino, Constitutio Limitum, (Trad. M. Clavel-Lévêque et alii), Nápoles, 1996, p. 24-25 (Th. 135); Ptolomeu, II, 5, 6.

42 Ainda que a localização destas povoações permaneça discutível, a falta de testemunhos epigráficos que as refiram sugere o seu fraco ou nulo desenvolvimento. Os talabrigenses conhecidos na Bética são límicos, não lusitanos.

43 Alarcão, Domínio, p.45.

44 N. R. Ursin, De Lusitania provincia romana, Helsínquia, 1884, p. 147; Ptolomeu, II, 5,7 . 
Celer Rectus (CIL II 2909, questor da Bética durante o governo de Trajano, é um bom exemplo.

Quem eram, afinal, os habitantes da Lusitânia romana? E quem eram então os Lusitanos? Do que dissemos até aqui é fácil depreender que o território da província, corresponde a um conjunto de regiões diferenciadas do ponto de vista geográfico e cultural e habitadas por vários grupos étnicos. Podemos considerar como elementos fundamentais da estrutura territorial da Lusitânia três regiões: a área a sul do Tejo, em tempos correspondente a uma parte da Turdetânia; a Lusitânia propriamente dita, entre o Tejo (Tagus) e o Douro (Durius); a Vetónia, também entre estes dois rios, ocupando a zona oriental da província. Se excluirmos esta última região, a Lusitânia romana apresenta uma configuração muito próxima da que conhece o actual território português a sul do Douro. Também a área correspondente a cada um dos conventos jurídicos em que a província foi dividida, em época ainda discutida $^{45}$, Emeritense, Pacense e Escalabitano, não se afasta significativamente das áreas regionais que considerámos, salvaguardando alguns pormenores de fronteira, em parte resultantes do traçado da rede viária romana e dos limites entre civitates. Quer isto dizer que as referidas entidades regionais correspondem a realidades naturais, capazes de condicionar os modelos administrativos e, por isso mesmo, mais ou menos receptivas às influências mediterrânicas.

As fontes antigas indicam a presença de vários povos na Lusitânia, sem que as regiões por eles ocupadas coincidam exactamente nos autores que escreveram sobre a província lusitana. Os principais, em parte já referidos, são Estrabão, Pompónio Mela, Plínio-o-Antigo, Ptolomeu e Marciano de Heracleia, que referem como povos estabelecidos na Lusitânia os Turdetanos, ou Túrdulos, os Celtas, os Lusitanos e os Vetões ${ }^{46}$. Havia, seguramente, diferenças culturais entre eles, nem sempre fáceis de identificar através do registo arqueológico. É o que sucede com os Túrdulos da fachada atlântica entre o Tejo e o Douro, cuja cultura material não produziu até agora testemunhos diferentes do que se conhece das populações célticas ou celtizadas, embora demonstrem uma abertura maior aos modelos romanos, em parte devido a contactos

45 Alarcão, Domínio, p. 58-60; M. Dopico Caínzos, Los conventus iuridici: origen, cronologia y naturaleza histórica, "Gerión”, 4, 1986, p. 265-283.

46 Jorge de Alarcão, O reordenamento territorial, "Nova História de Portugal", I, Lisboa, 1990, p. 352-359 (=Alarcão, Reordenamento). 
com o mundo mediterrânico anteriores à sua emigração do Sul da Península Ibérica ${ }^{47}$. Uma análise da Geografia de Ptolomeu permite verificar que os Lusitanos, não habitando toda a província, ultrapassam largamente a área própria da nação lusitana, no dizer de Estrabão48.

Desta forma, a Lusitânia afirma-se como uma criação romana, a partir da integração de regiões e de povos com características identitárias próprias num quadro administrativo único, artificial, cujas consequências moldaram o futuro. Temos, assim, uma realidade administrativa coerente, ainda que influenciada por particularismos, uma identidade política bem definida, a Hispania Ulterior Lusitania, composta por realidades muito diversas quanto aos aspectos sociais e económicos subjacentes à romanização. Elementos como tradição histórica, litoralidade, interioridade, influências atlântico-mediterrânicas e capacidade de transformação das estruturas indígenas condicionaram a recepção dos modelos romanos, justificando as diferenças que se identificam na sua dinâmica, diferenças que testemunham a diversidade existente no final da II Idade do Ferro.

O domínio romano, introduzindo elementos civilizacionais que determinaram um estilo de vida muito diferente daquele que existia nas comunidades indígenas (Fig. 4), constituiu um choque de consequências facilmente compreensíveis. Essas consequências são mais aparentes em certos aspectos do quotidiano e do cenário institucional, o que não deixa de concordar com a estrutura hierarquizada da sociedade romana, reproduzida em ambientes provinciais. Noutros aspectos, mesmo ideológicos, as semelhanças entre os padrões indígenas e certos conceitos romanos, típicos de sociedades da Idade do Ferro, facilitaram um processo de aculturação que, sem eliminar o predomínio incontestável do modelo civilizacional do colonizador, permitiram o desenvolvimento de intercâmbios relevantes e facilitaram um processo de integração pragmático, desenvolvido ao longo de vários séculos. É a este processo que devemos chamar romanização ${ }^{49}$.

47 A data da emigração túrdula continua vaga, entre o século VI e o século III a. C., embora seja possível situá-la no século IV a. C. Sobre este problema: Alarcão, Reordenamento, p. 357-358.

48 Ptolomeu, II, 5; Estrabão, III, 3, 3.

49 M. Salinas de Frías, Los Vettones. Indigenismo y romanización en el occidente de la Meseta, Salamanca, 2001, p. 23-27 (=Salinas de Frías, Vettones); G. Wolf, The unity and diversity of romanization, "Journal of Roman Archaeology", 5, 1992, p. 349-352 . 
Quando dizemos integração não estamos a defender a ideia de que as realidades indígenas desapareceram; não foi assim nem a política romana foi nesse sentido ${ }^{50}$. Aliás, não podemos esquecer que a sociedade romana também se modificou e as realidades do Baixo Império são distintas das que caracterizam o Alto Império, não deixando aquelas de contribuir para acelerar um processo de fusão cultural que os primeiros tempos do Império dificilmente poderiam desenvolver. Por exemplo, recordamos que a cidade de Pax Iulia (Beja), colónia de Augusto, possuía uma população constituída por colonos e por indígenas, com estatutos jurídicos diferentes, circunstância que se reflecte na existência de dois senados urbanos (CIL II $52=I R C P$ 233), à semelhança do que se conhece noutros locais do Império ${ }^{51}$. Os modelos romanos que mais impacte tiveram inicialmente foram os que se relacionavam com a estrutura política e económica, por razões que se prendem directamente com os objectivos da colonização. Esta circunstância não impediu, porém, que as cidades não privilegiadas, estipendiárias, desenvolvessem um estilo de vida à romana, assim como não impediu que os castella permanecessem ocupados por populações pouco influenciadas por muitas das práticas consideradas representativas da romanização.

Que forma de identidade lusitana surge com a romanização? Em relação a esta questão devemos ter em conta os elementos visíveis tanto como outros, menos aparentes, que diremos morais ou ideológicos, menos fáceis de identificar e quase sempre indirectamente. Na área político-cultural os modelos e padrões de comportamento romanos integraram perfeitamente a Lusitânia no mundo greco-latino do poder, das formas e dos hábitos, naturalmente à escala da realidade provincial. $\mathrm{O}$ urbanismo e os reflexos de uma estrutura social que repete o modelo oficial são testemunhos inequívocos do êxito desta romanização. Monumentos públicos como o forum de Conimbriga ou o tetrapylon de Capera (Cáparra) e inscrições repletas de nomes, deuses e cargos romanos transmitem uma ideia de uniformidade triunfante, sem que a diversidade provincial deixe de estar presente. Assim, por exemplo, as cidades privilegiadas não ultrapassam, até ao último quartel do século I,

50 M. Grant, O mundo de Roma, Lisboa, 1967, p. 123-124. Para uma visão crítica das relações culturais: C.R. Whittaker, Imperialism and culture: the roman iniciative, "Dialogues in Roman Imperialism", Portsmouth (RI), 1997, p. 143-160.

51 Vasco Mantas, Em torno do problema da fundação e estatuto de Pax Iulia, “Arquivo de Beja”, II-III, série III, 1996, p. 51-54; Paulo, Dig., 50, 5, 8. 
a linha do Tejo. Capitais de civitates, como Idanha-a-Velha (Civitas Igaeditanorum), monumentalizam-se ou reformam o seu equipamento urbano, mas a comparação destas com as cidades do Sul resulta esclarecedora de diferenças essenciais quanto ao ambiente em que se implantam os modelos romanos (Fig. 5).

A análise da repartição dos tria nomina característicos da denominação romana não é menos significativa quanto à difusão dos quadros da romanidade oficial: o núcleo regional do Museu do Fundão em quinze epígrafes apenas conta com uma referência, enquanto que no Museu de Torres Vedras em treze inscrições ocorrem doze indivíduos identificados com os tria nomina ${ }^{52}$. A análise da antroponímia indígena presente nas inscrições luso-romanas não é menos expressiva quanto às diferenças regionais da romanização: uma cidade como Liberalitas Iulia Ebora (Évora) conta com $2 \%$ de nomes indígenas, enquanto que em Collipo (S. Sebastião do Freixo) ela sobe já para 35\% e em Caurium (Coria) atinge valores próximos dos $70 \%$, média registada na província de Salamanca 53 .

A comparação entre cidades como Aeminium (Coimbra), Salmantica (Salamanca) ou Balsa (Luz de Tavira) permite, naturalmente, identificar as estruturas oficiais da sociedade romana e os monumentos urbanos que lhe são próprios e, simultaneamente, verificar a presença de elementos distintivos. A influência mediterrânica é muito mais nítida, e não apenas por razões de ordem geográfica, em Balsa (Fig. 6), cidade cuja população representa bem a diversidade de contactos do mundo mediterrânico na época romana e uma certa maneira de estar que em tudo corresponde às áreas meridionais do Império $^{54}$.

52 J. L. Vaz, Inscrições romanas do Museu do Fundão, "Conimbriga", XVI, 1977, p. 10-11; Vasco Mantas, Inscrições romanas do Museu Municipal de Torres Vedras, "Conimbriga", XXI, 1982, p. 86, 94 (=Mantas, Museu).

53 Mantas, Museu, p. 86; J. Sanchéz Albalá/D. Vinagre Nevado, Corpus de inscripciones latinas de Coria, Coria, 1998, p. 119-126; Salinas de Frías, Vettones, p. 151. $\mathrm{Na}$ região de Cáceres, apesar da presença de uma colónia romana, Norba Caesarina, a onomástica indígena representa $75 \%$ do total: Beltran Lloris, p. 58.

54 M. Salinas de Frías, Las ciudades romanas de Lusitania Oriental: su papel en la transformación del territorio y la sociedad indígena, "Les Villes de Lusitanie Romaine”, Paris, 1990, p. 255-264; Vasco Mantas, As cidades marítimas da Lusitânia, "Les Villes de Lusitanie Romaine”, Paris, 1990, p. 182-205. Sobre o ambiente mediterrânico: M. Aymard, Espaces, "La Mediterranée”, (Dir. F. Braudel), Paris, 1985, p. 191-223 . 
Fora das grandes cidades ou das áreas de particular interesse económico, que se passava? Tivemos já algumas indicações acerca da persistência das estruturas indígenas, em especial a nível da religião, da onomástica e das organizações suprafamiliares. O caso da religião é particularmente interessante pelo simples facto de ilustrar uma vincada diferença cultural entre o Norte da província, com dezenas e dezenas de divindades indígenas conhecidas através da epigrafia, e a sua extrema raridade a sul do Tejo, não ultrapassando o limite meridional que Ptolomeu assinala para os Lusitanos, indício seguro de um enorme influxo cultural mediterrânico abaixo do vale do Tejo ${ }^{55}$. Quanto à onomástica, indicador dos mais significativos, os nomes indígenas não só sobrevivem como são dominantes em muitas regiões da Lusitânia, como a epigrafia demonstra, perdendo representatividade no Sul56. É muito interessante a relação existente entre a onomástica indígena e determinados monumentos funerários, em especial as estelas de topo semicircular decoradas com motivos ditos astrais, muito vulgares no interior da Lusitânia, mas que ocorrem também em áreas litorais da província (Fig. 7), como nos arredores de Olisipo e de Collipo ${ }^{57}$.

$\mathrm{O}$ mesmo não se verifica com os testemunhos das organizações suprafamiliares tipicamente indígenas, como as gentilitates, gentes e cognationes, que apenas se encontram documentadas na Lusitânia profunda, a norte do Tejo. Esta relação com uma organização social pré-romana reflecte-se igualmente nas indicações de origo que frequentemente ocorrem na epigrafia própria de ambientes culturais indígenas, sob a forma de nomes de populi ou de obscuros povoados ${ }^{58}$.

Em torno da continuidade de factores sociais e culturais indígenas e do seu relacionamento com os padrões romanos desenvolveu-se, na segunda metade do século XX, uma acerba discussão académica, não poucas vezes influenciada por questões ideológicas do mundo contemporâneo, discussão centrada na interpretação dos referidos factores como testemunhos de uma vontade de resistência ao domínio romano. Não cremos que a diversidade de situações não enquadradas no modelo

55 Alarcão, Domínio, p. 154-155; Encarnação, IRCP, p. 799-807.

56 Sobre a onomástica indígena no convento pacense: Encarnação, IRCP, p. 777.

57 Mantas, Museu, p. 53-71, 79-83; J. Pedro Bernardes, Romanização e sociedade rural na civitas de Collipo, "Sociedad y Cultura en Lusitania Romana", Mérida, 2002, p. 430-432.

58 Salinas de Frías, Vettones, p. 165-178. 
romano de sociedade e de cultura possa ser interpretada como uma manifestação de repúdio da presença romana na Lusitânia. Tal circunstância deve-se, basicamente, à dinâmica da romanização, que não afecta por igual a população indígena e que depende em larga medida de iniciativas privadas. Neste cenário, é natural que as elites locais tenham assumido uma posição central, a ponto de se confundirem estes notáveis e seus familiares como representantes exclusivos da franja romanizada das sociedades provinciais, o que é um exagero redutor de uma realidade mais complexa. Os Romanos tiveram a preocupação, a partir dos finais da República, de organizar o espaço que dominavam através de soluções flexíveis (Fig. 8), integradas num modelo comum no qual todas as províncias se podiam reconhecer como parte de Roma. Admitiam as diferenças, sempre que não fossem contrárias aos seus valores e interesses, pelo que a continuidade de certas características da sociedade indígena é completamente normal.

É na região setentrional da Lusitânia que os modelos romanos se tornam mais notados, em parte por se situarem numa região pouco ou nada mediterrânica, rudemente tradicional, como já tivemos oportunidade de frisar. Numa área em que os elementos culturais indígenas continuam presentes e activos, os testemunhos da colonização e da aculturação, mais isolados do ambiente tradicional, impõem-se como algo estranho, mas que representa o poder e o modelo a copiar. Em Cória, esclarecedoramente, uma das inscrições de feitura mais clássica é uma placa em que se recorda uma Iulia Avita olisiponense 59 . No interior da Lusitânia, com uma população constituída esmagadoramente por peregrini e adtributi com reduzidas possibilidades de ascensão jurídica, uma das quais era através do serviço militar nas tropas auxiliares, a romanização reflecte uma realidade muito diferente da que prevalecia no litoral e a sul do Tejo onde, por exemplo, a maioria dos militares conhecidos são naturais de cidades privilegiadas e, como tal, cidadãos romanos ${ }^{60}$.

O processo de aculturação que se desenvolveu na Lusitânia promoveu fenómenos de síntese muito curiosos, característicos de uma sociedade colonial gradualmente participada por elementos indígenas romanizados, tendendo a constituir um todo com valores e padrões de

59 Sánchez Albalá/Vinagre Nevado, p. 57, n. ${ }^{\circ} 43$.

60 Petit, p. 277-279, 283-284; N. Santos Yanguas, Las cohortes lusitanorum en el ejercito romano, "Conimbriga”, XVIII, 1979, p. 171-202; Le Roux, Armée, p. 319-340 . 
comportamento semelhantes. Este processo de fusão é mais nítido em determinadas áreas do quotidiano, como sucede com aspectos da prática religiosa. Se entre os indígenas Júpiter foi a divindade romana mais divulgada, por razões que se relacionam tanto com a imagem do poder como com um processo de identificação próximo da interpretatio, o grande santuário de Endovélico, em S. Miguel da Mota, faculta um brilhante exemplo da síntese e da mistura cultural que ocorreu durante o Alto Império ${ }^{61}$.

Terminaremos com uma reflexão sobre a identidade lusitana, questão que merecia um desenvolvimento que não podemos concederlhe neste momento. Será viável conceber uma pátria lusitana, na linha do pensamento de Cícero sobre a dupla pertença ${ }^{62}$, ou não é possível ultrapassar o conceito da província como simples quadro administrativo? As referências à Lusitânia como origo não são vulgares fora da província e ocorrem quase sempre num contexto muito relacionado com o quadro administrativo oficial ou seu equivalente, como no caso do culto imperial ou do serviço militar63, sobretudo nas tropas auxiliares, pois entre os legionários prevalece a indicação da civitas. Claro que há excepções, como a inscrição rupestre junto ao farol da Corunha em que o arquitecto do mesmo, G. Sevius Lupus, se identifica como lusitano e eminiense, aliás num cenário não completamente estranho ao culto imperial ${ }^{64}$. Porém, num ambiente privado, a epígrafe funerária do diffusor olearius de Lisboa M. Cassius Sempronianus, achada em Tocina, perto de Sevilha, apenas indica como origo a cidade de Olisipo ${ }^{65}$.

Numa grande confederação de cidades como era o Império Romano, os aspectos jurídico-administrativos eram fundamentais na con-

61 Alarcão, Domínio, p. 167-168; Encarnação, IRCP, p. 553, 561-629, 800-805; Divindades indígenas da Lusitânia, "Conimbriga”, XXVI, 1987, p. 10-13. O santuário, situado perto de Terena, é presentemente tema de um projecto de investigação dirigido por Amílcar Guerra, muito promissor: A. Guerra/Th. Schattner/C. Fabião, Notícia, "Conimbriga", LXI, 2002, p. 295-297.

62 Cícero, De Leg., II, 5.

63 R. Étienne, Le culte impérial dans la Péninsule Ibérique d'Auguste a Dioclétien, Paris, 1958, p.121-175; Le Roux, Armée, p. 184-189, 218-223.

$64 \mathrm{P}$. Le Roux, Le phare, l'architecte et le soldat: l'inscription de la Corogne (CIL II 2559), "Miscellanea Greca e Romana”, XV, 1990, p. 133-145.

65 J. G. Fernández, Nueva inscripción de un diffusor olearius en la Bética, "Producción y Comercio del aceite en la Antigüedad", II, Madrid, 1983, p. 183-191; M. F. Loyzance, A propos de Marcus Cassius Sempronianus Olisiponensis, diffusor olearius, “Revue des Études Anciennes”, LXXXVIII, 1986, 1-4, p. 273-285. 
cepção da cidadania. Na Lusitânia, entre a civitas e o Império não intervém, normalmente, nenhuma entidade que sugira a existência de um sentimento provincial forte. Aqui, como é normal, a província é um conjunto de territórios e de cidades com estatutos diferenciados que vão da colónia de direito itálico ao pagus, enquadrados por uma administração que deixava bastante liberdade aos poderes locais ${ }^{66}$. As cidades escolhem patronos, enviam directamente legações a Roma, gozam de competências jurídicas e podem unir-se para resolver situações concretas, como no caso da construção da ponte de Alcântara, sobre o Tejo (CIL II 760).

Uma longa convivência pacífica interna, a convergência de interesses, a facilidade de comunicações e a existência de uma administração centralizada e promotora de ideais supra-regionais contribuíram para o desenvolvimento de um certo sentimento de identidade hispânica, que parece já bastante avançado no século IV, quando Mérida assume a capitalidade da Diocese das Hispânias, com a Tingitânia adstrita. Talvez se possa ver o reflexo desta identidade superior ao conceito de uma identidade provincial na referência no Código de Teodósio aos navicularii Hispani ${ }^{67}$.

Esta afirmação de hispanidade é muito clara em Santo Isidoro de Sevilha, nomeadamente quando se trata do conflito entre Visigodos e Bizantinos, pelo domínio do Sul da Península ${ }^{68}$. A invasão muçulmana dará lugar a um novo influxo mediterrânico e a um novo episódio da história peninsular. Novidade ou simples recomeço? Julgamos que se tratou, afinal, de um fenómeno de continuidade, característico de uma região atlântica profundamente ligada ao Mediterrâneo. Recordemos o que sobre este mar escreveu Jaime Cortesão: Verdadeiramente, até à Renascença, uma única civilização influiu ou teve o propósito de influir no Mundo: - a mediterrânea. O facho de Prometeu passou de uma idade para a outra e de mão em mão, mas sempre ali, às suas margens ${ }^{69}$.

66 Jorge de Alarcão, O estado e o governo local, "Nova História de Portugal", I, Lisboa, 1990, p. 386-390; J.M. Abascal/U. Espinosa, La ciudad hispano-romana. Privilegio y poder, Logronho, 1989, p. 193-231.

67 E. Stein/J.R. Palanque, Histoire du Bas-Empire, I, Paris, 1959, p. 447; Cod. Theod., XIII, 5, 4; 5, 8; R. Étienne, Mérida, Capital du vicariat des Espagnes, "Homenaje a Saenz de Buruaga”, Badajoz, 1982, p. 201-207.

68 F. Lot, La fin du monde antique et le début du moyen âge, Paris, 1968, p. 306.

69 Jaime Cortesão, Itália azul, "Obras Completas”, VII, Lisboa, 1965, p. 12. 


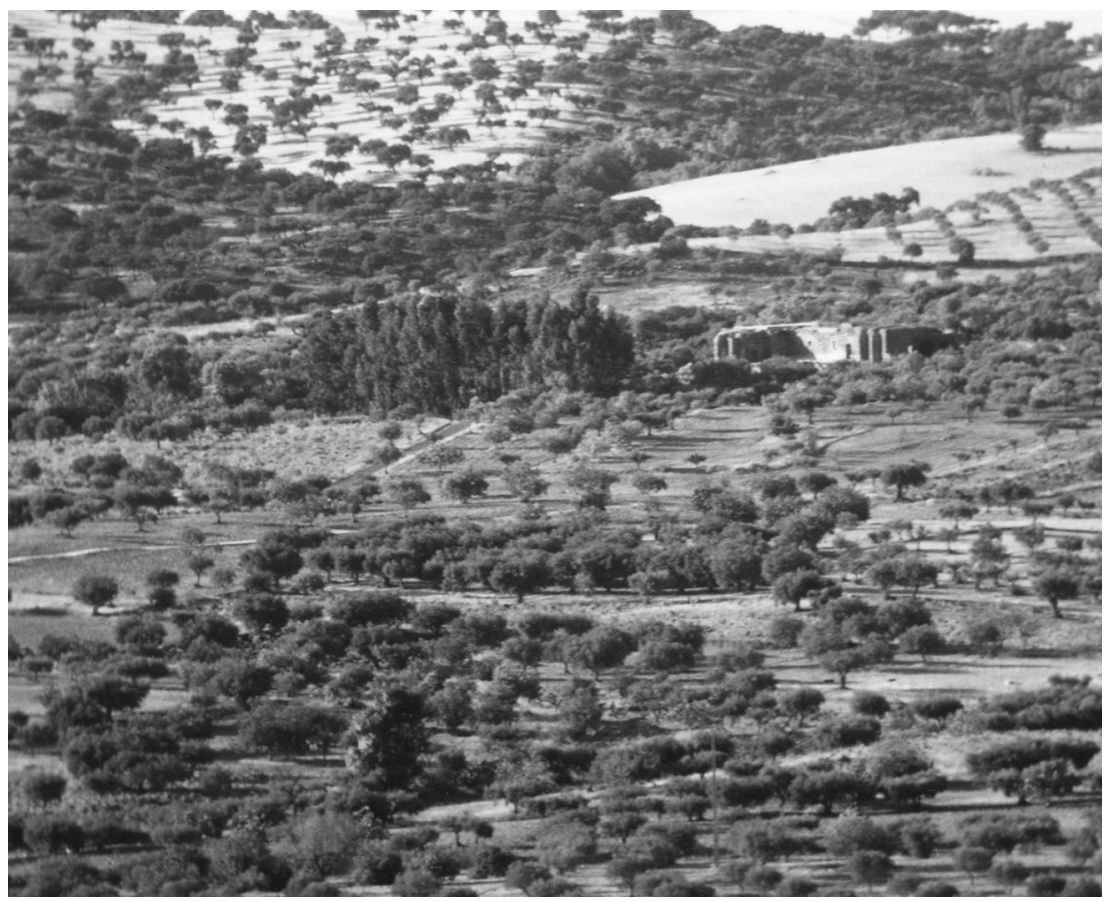

FIG. 1 - Paisagem romanizada no Alentejo: ruínas da villa de S. Cucufate, Vidigueira. 


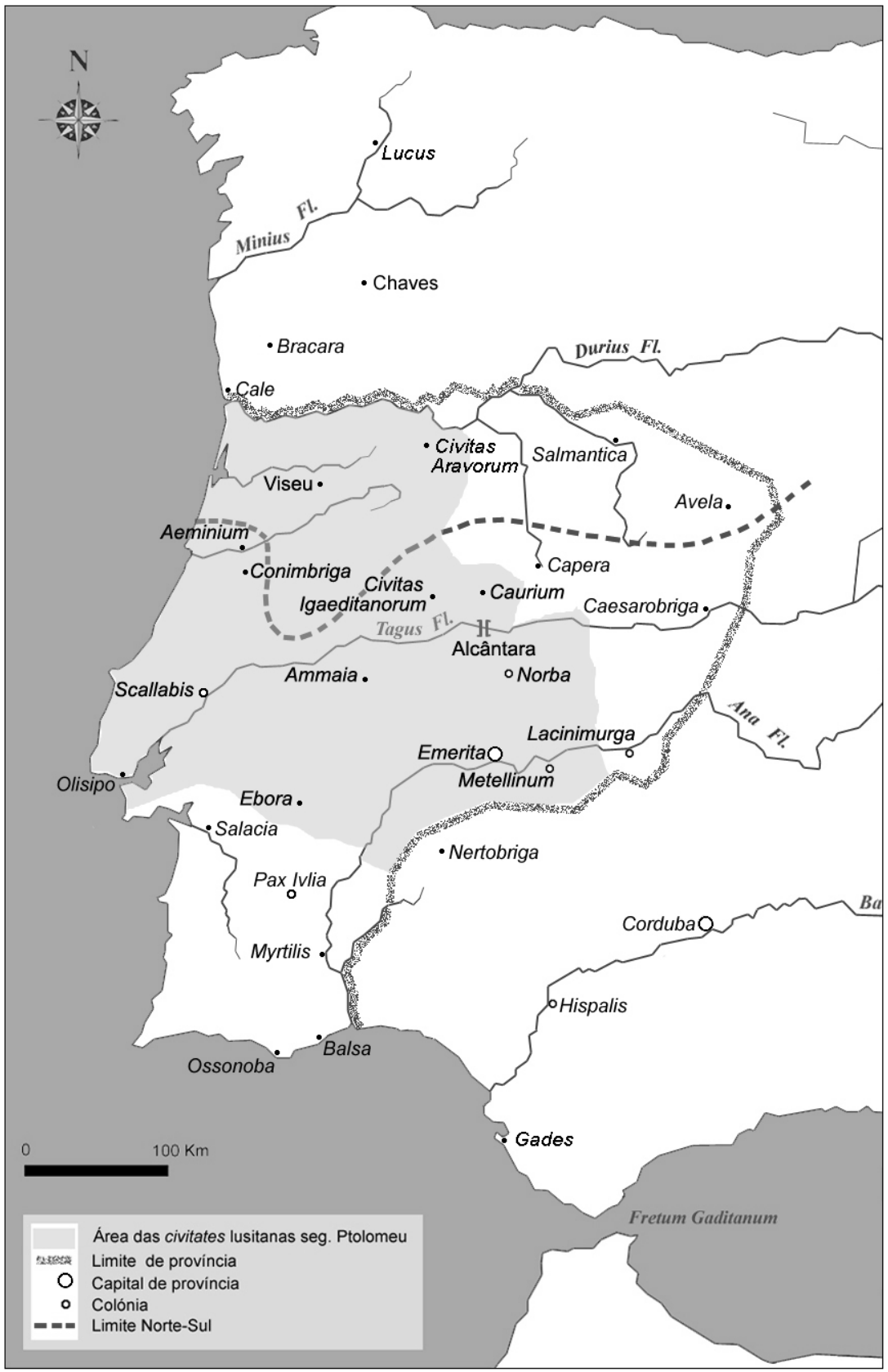

FIG. 2 - A Lusitânia e os Lusitanos no século II. 


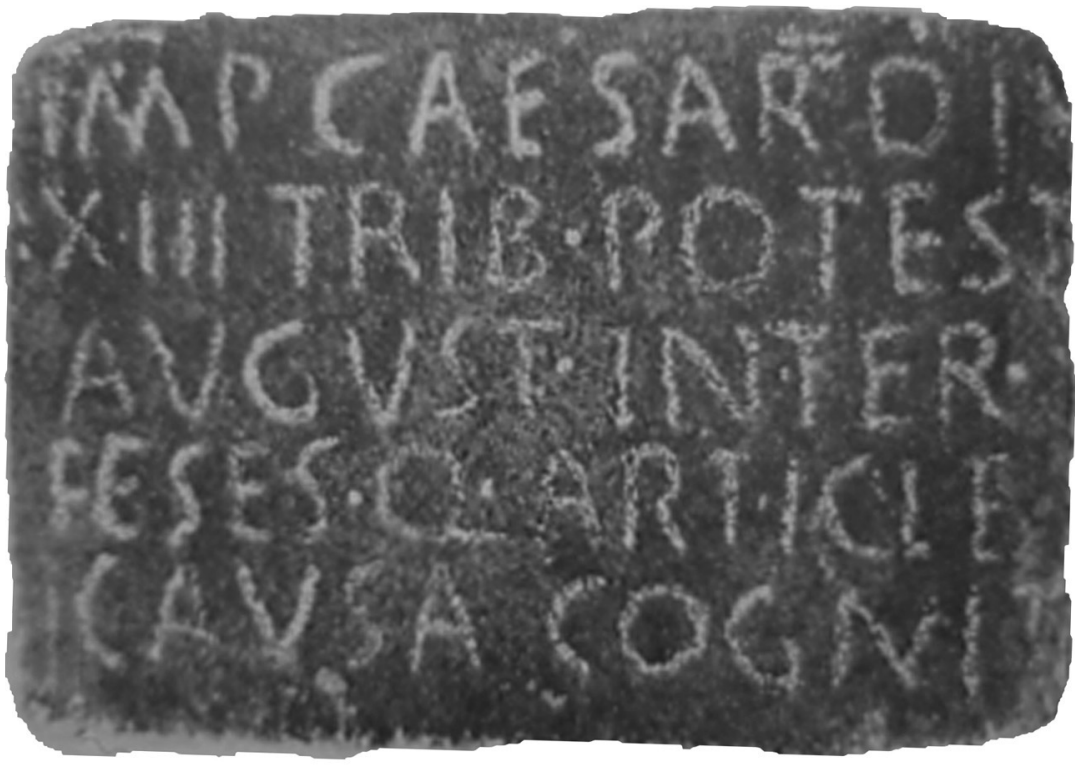

Fig. 3 - A Pax Romana em acção: marco demarcatório de povos na Serra do Caramulo.

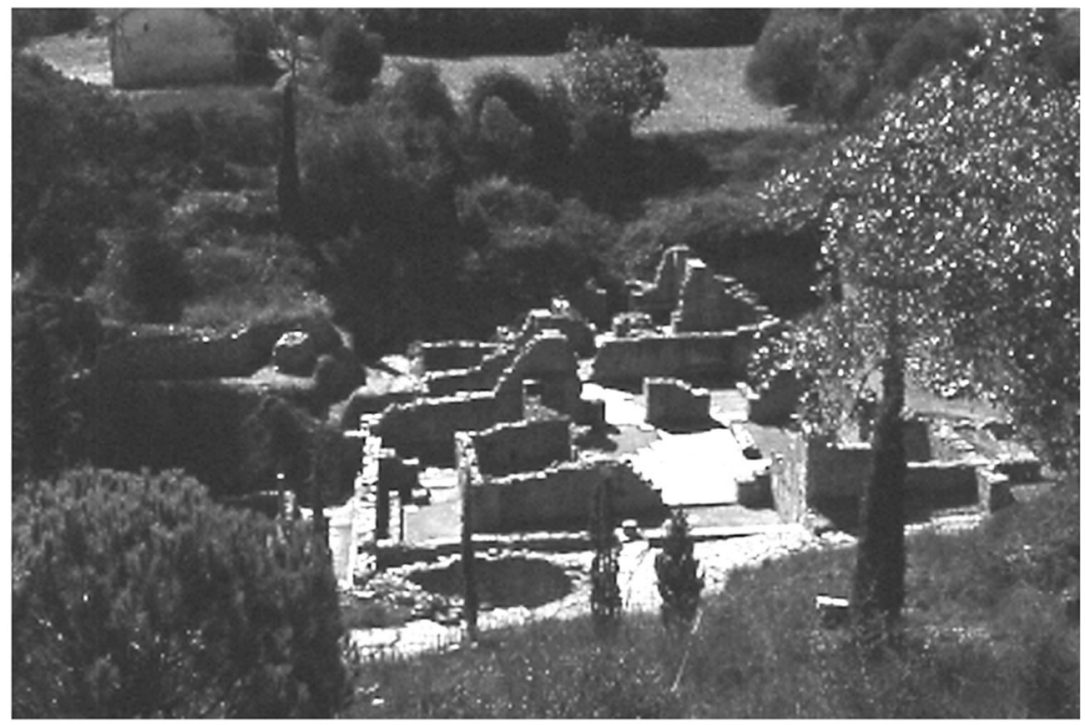

FIG. 4 - A romanização do quotidiano: ruínas das termas de Mirobriga (Santiago do Cacém). 


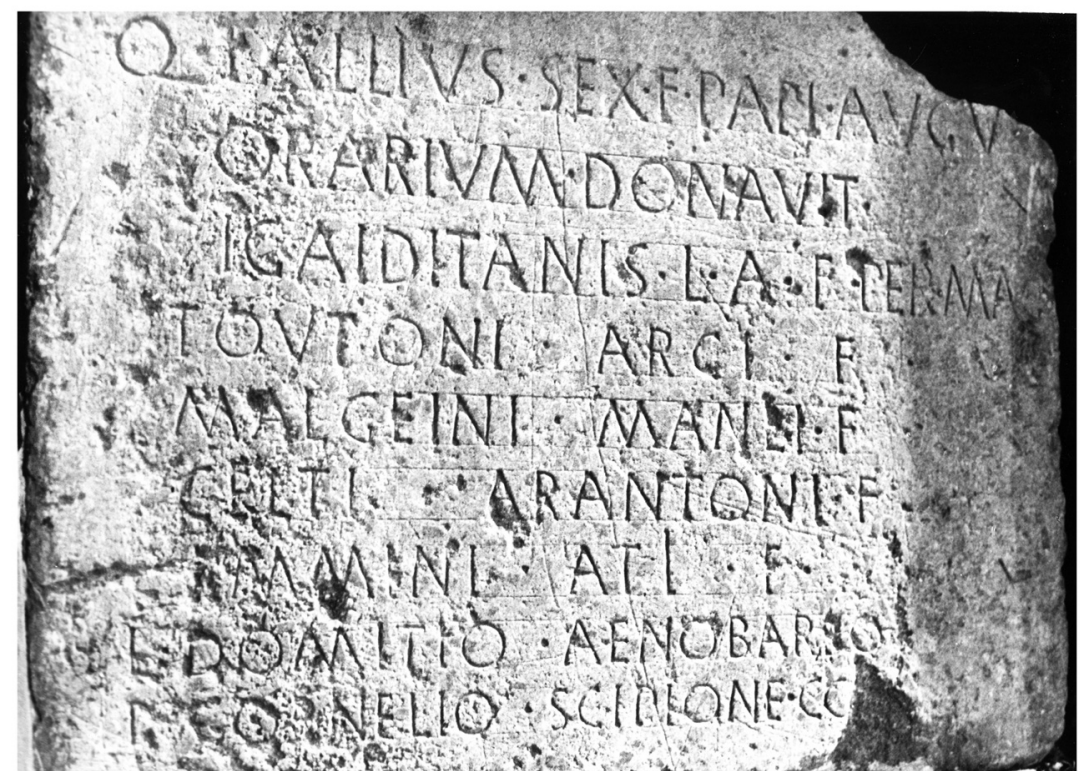

FIG. 5 - A romanização da sociedade indígena: inscrição de Idanha-a-Velha comemorando a oferta de um relógio à cidade, no ano 16 a. C. 


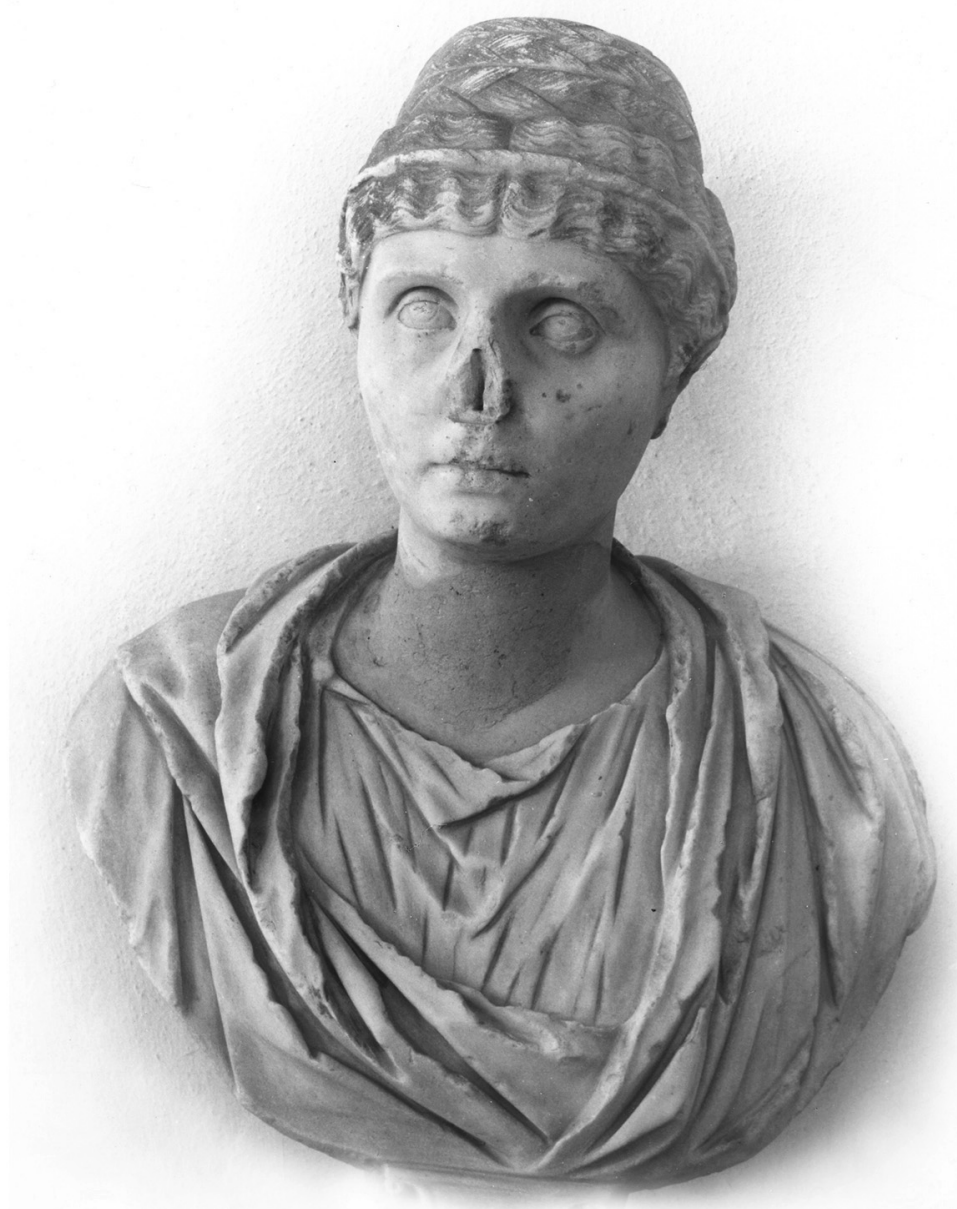

FIG. 6 - A estética greco-romana na Lusitânia: busto feminino do período antonino achado em Balsa (Museu Regional de Évora). 


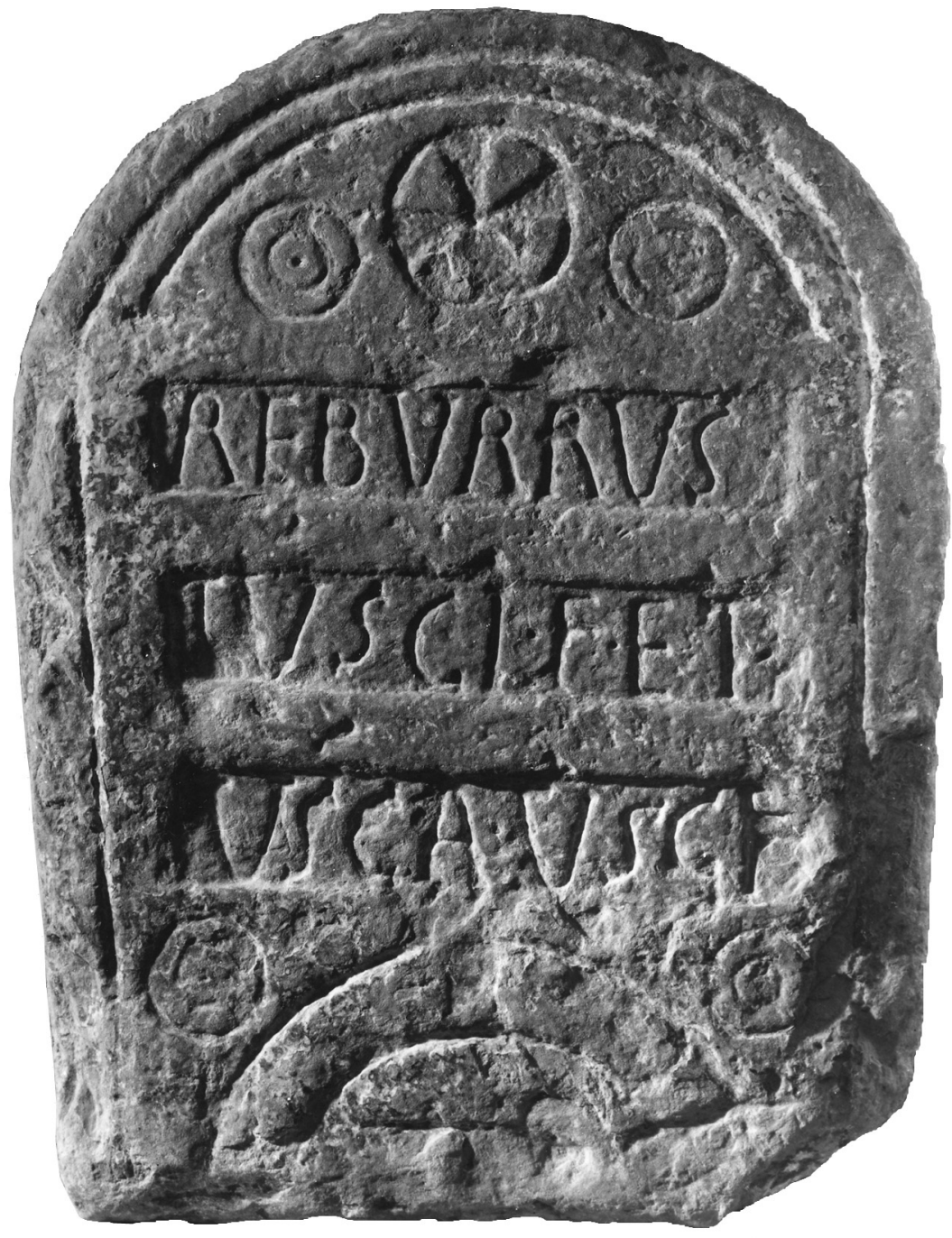

FIG. 7 - Indigenismo e aculturação: estela funerária da Quinta da Portucheira (Museu Municipal de Torres Vedras). 


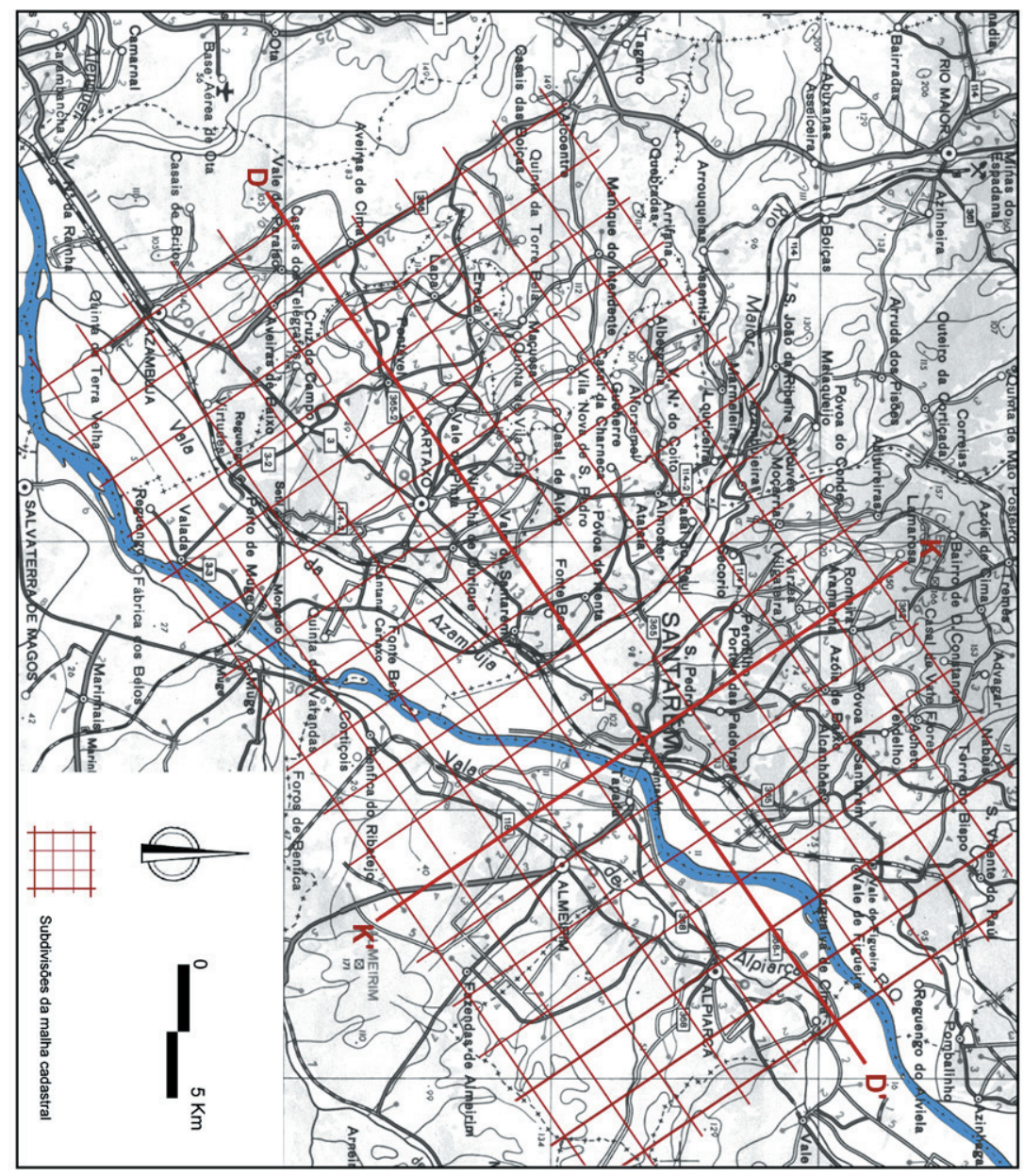

FIG. 8 - Território e romanização: centuriação colonial de Scallabis (Santarém). 